Article

\title{
Strategic Offering for Wind Power Producers Considering Energy and Flexible Ramping Products
}

\author{
Xin Fang, Venkat Krishnan and Bri-Mathias Hodge * \\ National Renewable Energy Laboratory, Golden, CO 80401, USA; xin.fang@nrel.gov (X.F.); \\ Venkat.Krishnan@nrel.gov (V.K.) \\ * Correspondence: Bri.Mathias.Hodge@nrel.gov
}

Received: 20 March 2018; Accepted: 8 May 2018; Published: 13 May 2018

\begin{abstract}
The increasing deployments of renewable generation methods, such as wind, affects the flexibility of electric power system operating due to their inherent variability and uncertainty. To mitigate this, power systems need flexible resources. This paper investigates the potential for wind power to provide flexible ramping products in the real-time market, an additional value stream to the energy it provides. The proposed model for wind power's strategic offering is formulated as a bi-level optimization problem with wind profit maximization at the upper level and the independent system operator's economic dispatch — considering both the energy balance and the flexible ramping requirement to counter uncertainty-at the lower level. This bi-level model is converted to a mathematical program with equilibrium constraints (MPEC) by recasting the lower level problem with its Karush-Kuhn-Tucker optimality conditions. Then, through strong duality theory and the big-M method, the MPEC model is converted to a mixed-integer linear programming model. The opportunity cost and the price for wind power-providing ramping products are analyzed. Numerical examples based on a 5-bus network are presented to verify the proposed model and concept.
\end{abstract}

Keywords: wind power; flexible ramping; strategic offers; electricity market; mathematical program with equilibrium constraints

\section{Introduction}

Variable renewable energy integration is increasingly changing the generation portfolio of electric power systems in the United States and other countries [1]. The inherent characteristics of such energy types - uncertainty and variability—bring significant challenges to the electric power system and market operations [2]. Usually, to offset these uncertainties, systems procure additional reserve capacity, such as a spinning/non-spinning reserve in their day-ahead, security-constrained unit commitment (SCUC) [3,4]; however, in the real-time market, this reserve might not be effective to handle ramp-shortage problems caused by significant variations in the load and renewable output [5] during short time periods. When there is a ramp shortage in real-time operation, the system generation dispatch and the market-clearing price are distorted from reasonable values. Therefore, the ability to maintain adequate ramp capability is an urgent issue in real-time market operations.

Currently, some independent system operators (ISOs) have launched and implemented market designs for flexible ramping products, such as the flexi-ramp product in the real-time market by the California Independent System Operator (CAISO) and the ramp capability product in the day-ahead and real-time markets by the Midcontinent Independent System Operator (MISO) [6,7]. In these designs, specifically in the real-time markets, flexible ramp capacity is procured by adding ramp requirements to the deterministic real-time economic dispatch (RTED) models [8], such that the ramp product is co-optimized with energy and other ancillary services in the market. 
In these markets, wind power is usually modeled as a source that contributes to the ramp requirement; however, using wind power to increase a system's flexibility-including modeling it as a flexible ramp capacity provider-is attracting more attention due to the rapidly increasing penetration of wind power [9-11]. Previous literature has analyzed system flexible ramp requirements and the impacts of ramp products on market clearing [12-16]. The impact of wind power on flexible ramping was reviewed in $[15,16]$. In these studies, the impacts of flexible ramping on a system's reliability and its operation costs were analyzed from the viewpoints of system operators. Further, the benefits of wind power providing ramp products were analyzed in $[5,9,17]$ to improve system reliability and reduce ramp scarcity.

However, large-scale wind power plants in systems are independent profit seekers [18-21], i.e., the goal of their market operation is to maximize their profits. Therefore, it is necessary to analyze the impact of a flexible ramping service from wind power from the viewpoints of the wind power producer (i.e., their revenues) and to devise strategic wind power offers in the real-time market for both energy and ramping products. To this effect, this paper develops a strategic offering model for wind power by proposing a bi-level optimization model with wind power profit maximization at the upper level and the ISO's RTED co-optimization of energy and ramp requirements at the lower level.

The rest of this paper is organized as follows: Section 2 illustrates the flexible ramping requirement in real-time market operation. Section 3 proposes the actual solution to solve the strategic offer co-optimization model for both energy and ramping products from wind power. This includes the procedure of transforming the bi-level optimization model into a mathematical program with equilibrium constraints (MPEC) model and the conversion from the MPEC to a mixed-integer linear programming (MILP) problem. Section 4 demonstrates the simulation results and numerical analyses of the PJM 5-bus system to verify the proposed method. Section 5 presents the concluding remarks and discusses future work.

\section{Illustration of Flexible Ramping}

\subsection{System Level Flexible Ramping Requirement}

To reduce the ramp scarcity caused by the uncertainties in the net-load (load and renewable generation) and maintain system reliability, a flexible ramping product has been introduced in the security-constrained economic dispatch problem by the ISOs [5-7,9]. The discussion and formulation of the flexible ramping product in this paper is in line with typical ISO practices, but includes an improvisation that separates the ramping requirements by the most likely forecasts and their uncertainties.

To further elaborate, Figure 1 demonstrates flexible ramping during different time intervals. The solid dark dots are the most likely expected load forecasts at every interval. The red short lines and the yellow short lines are the upper and lower bounds of the forecasted load (due to uncertainties) at every time interval. From $t 0$ to $t 1$, because the forecasted load's lower bound at $t 1$ is larger than the forecasted load at $t 0$, there is no flexible ramp-down capacity requirement from $t 0$ to $t 1$. If the forecast uncertainty drove the load's lower bound in $t 1$ further below the load forecast at $t 0$, there would be a flexible down-ramp requirement. However, there is flexible ramp-up requirement, which includes both the most likely anticipation of the load ramp-up (i.e., load $(t 1)-\operatorname{load}(t 0)$ ) and the forecast uncertainty that set the load upper bound in $t 1$.

Similarly, for $t 1$ to $t 2$, there is a flexible ramp-up requirement (no ramp-down requirement) and for $t 2$ to $t 3$, there is a flexible ramp-down requirement (no flexible ramp-up requirement). From $t 3$ to $t 4$, there are both flexible ramp-up and flexible ramp-down requirements. It should be noted that while the flexible ramp-down requirement in this case comprises both the expected and uncertain portions of the forecasted load down-ramp, the flexible ramp-up requirement is entirely due to the uncertainty in the forecasted load up-ramp (i.e., most likely forecast plus the uncertainty driving the upper bound forecast at $t 4$ above the forecasted load( $t 3)$ by a small portion). 


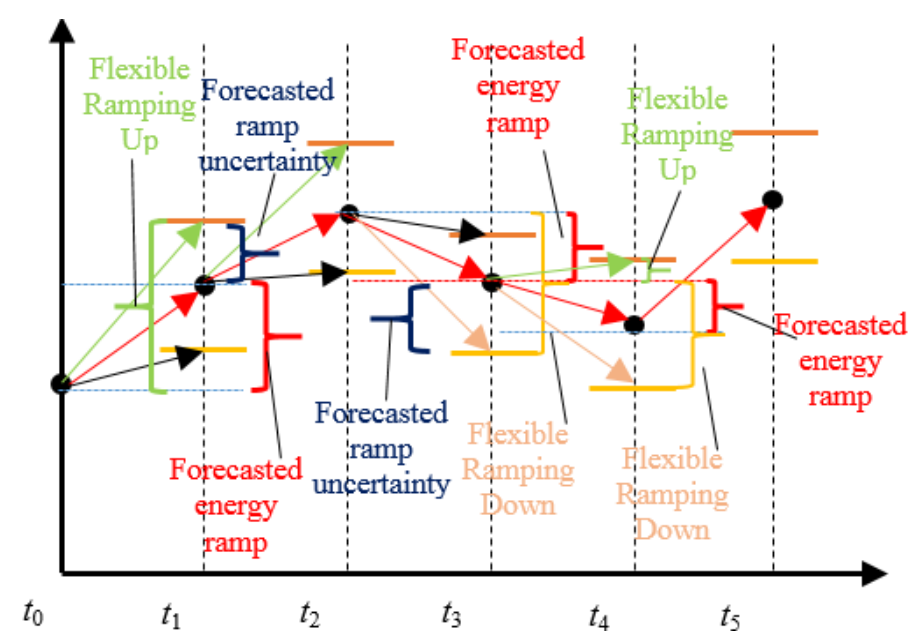

Figure 1. Illustration of the flexible ramping product, including expected and uncertain portions of ramp-up and ramp-down requirements.

From Figure 1, the flexible ramp capacity requirement can be derived. From $t 0$ to $t 1$, the flexible ramp-up requirement is

$$
F R U R_{t 0}=\overline{L_{t 1}}-L_{t 0}
$$

From $t 3$ to $t 4$, the flexible ramp-up requirement is

$$
F R U R_{t 3}=\overline{L_{t 4}}-L_{t 3}
$$

Generally, the flexible ramp-up capacity for interval $t$ is given as

$$
F R U R_{t} \geq \bar{L}_{t+1}-L_{t}
$$

Similarly, the flexible ramp-down capacity for interval $t$ is given as

$$
F R D R_{t} \geq L_{t}-\underline{L}_{t+1},
$$

where $L$ is the system's total load, and $\bar{L}_{t+1}$ and $\underline{L}_{t+1}$ are the forecasted load upper and lower levels.

\subsection{Wind Power Ramp Forecast}

The wind power ramp forecast corresponds to the difference between $P_{w, i}^{r t}$ and $P_{w, i}^{r t+1}$ in model (8). $P_{w, i}^{r t}$ is the available wind power output forecast at the current interval, and $P_{w, i}^{r t+1}$ is the available wind power output forecast at the next interval.

Therefore, the difference between $P_{w, i}^{r t}$ and $P_{w, i}^{r t+1}$ represents the endogenous wind power ramp. When the ramp directions of the wind power and the load coincide, the wind power ramp can alleviate the system's ramp shortage. When their directions are opposite, the system requires plenty of ramp resources.

\section{Strategic Offering for Wind Power Considering the Flexible Ramping Product}

In the real-time market, the wind power producer will receive two parts of a payment if it provides both the energy and flexible ramping products, as shown in the objective function (5). The first term is the revenue from the energy provided, and the second and third terms are the revenues from providing flexible ramp-up and ramp-down products.

$$
R_{w}=\sum_{i \in A}\left(\pi_{i} P_{w, i}+\alpha F R U_{w, i}+\beta F R D_{w, i}\right),
$$




$$
\begin{gathered}
P_{w, i}+F R U_{w, i} \leq P_{w, i}^{\max }, \\
P_{w, i}-F R D_{w, i} \geq 0,
\end{gathered}
$$

where $A$ is the bus set connecting wind farms of the wind power producer, and $P_{w, i}^{\max }$ is the maximum available wind power output. If the wind provides flexible ramping up product, $F R U_{w, i}>0$, then $P_{w, i}^{\max }$ is the maximum available power output at the next time interval. While, if the wind does not provide a flexible ramping up product, $F R U_{w, i}=0$, then $P_{w, i}^{\max }$ is the maximum available power output at the current time interval.

\subsection{Bi-Level Strategic Offering Model for Wind Power}

The objective of the wind power strategic offering is to maximize its net revenue considering its participation in the flexible ramping product market. In this strategic offering model, the locational marginal price (LMP) for energy and the market-clearing price for flexible ramping products are obtained from the ISO's RTED [18,22]. Therefore, the strategic offering problem is formulated as a bi-level problem in (8)-(25), where FRUR/FRDR are the system flexible ramp-up/down requirements, which are obtained from the forecast shown in Figure 1. The ISO market-clearing model includes the offer prices for wind-providing ramp products. A more detailed analysis on these prices is performed in Section 4.

$$
\begin{aligned}
& \text { Maximize } R_{w}=\sum_{i \in A}\left(\pi_{i} P_{w, i}+\alpha F R U_{w, i}+\beta F R D_{w, i}\right), \\
& \text { s.t. } \forall \pi_{i} \in \arg \left\{\min \sum_{i=1}^{N}\left[\begin{array}{c}
c_{i} G_{i}+c_{i}^{w} P_{w, i}+c_{u, i}^{w} F R U_{w, i}+c_{d, i}^{w} F R D_{w, i} \\
+\rho \Delta D+\gamma\left(\Delta r^{u}+\Delta r^{d}\right)
\end{array}\right]\right. \text {, } \\
& \text { s.t. } \sum_{i=1}^{N} G_{i}+P_{w, i}=\sum_{i=1}^{N} D_{i}: \lambda \text {, } \\
& \sum_{i=1}^{N} D_{i}+\Delta D=\sum_{i=1}^{N} D_{i}^{0}: \sigma, \\
& 0 \leq D_{i} \leq D_{i}^{0}: \tau_{i}^{\min }, \tau_{i}^{\max }, \\
& -L D_{l} \leq \sum_{i=1}^{N} G S F_{l-i}\left(G_{i}+P_{w, i}-D_{i}\right) \leq L U_{l}: \mu_{l}^{\min }, \mu_{l}^{\max }, \\
& G_{i}+F R U_{i} \leq G_{i}^{\max }: \omega_{i}^{\max }, \\
& G_{i}-F R D_{i} \geq G_{i}^{\text {min }}: \omega_{i}^{\text {min }}, \\
& P_{w, i}+F R U_{w i} \leq P_{w, i}^{\max }: \varphi_{i}^{\max }, \\
& P_{w, i}-F R D_{w, i} \geq 0: \varphi_{i}^{\min }, \\
& 0 \leq P_{w, i} \leq P_{w, i}^{r t}: \theta_{i}^{\min }, \theta_{i}^{\max }, \\
& F R U_{i} \leq R R_{i}^{u}: \vartheta_{i}^{u} \\
& F R D_{i} \leq R R_{i}^{d}: \vartheta_{i}^{d}, \\
& \sum_{i=1}^{N}\left(F R U_{i}+F R U_{w, i}\right)+\Delta r^{u}=F R U R: \alpha, \\
& \sum_{i=1}^{N}\left(F R D_{i}+F R D_{w, i}\right)+\Delta r^{d}=F R D R: \beta, \\
& F R U_{i} \geq 0: \delta_{i}^{u} ; F R D_{i} \geq 0: \delta_{i}^{d}, \\
& F R U_{w, i} \geq 0: \delta_{w, i}^{u} ; F R D_{w, i} \geq 0: \delta_{w, i}^{d}, \\
& \left.\Delta r^{u} \geq 0: \varepsilon^{u} ; \Delta r^{d} \geq 0: \varepsilon^{d}\right\},
\end{aligned}
$$




$$
\begin{aligned}
\mathbf{L}(\boldsymbol{x})= & \sum_{i=1}^{N}\left[c_{i} G_{i}+c_{i}^{w} P_{w, i}+c_{u, i}^{w} F R U_{w, i}+c_{d, i}^{w} F R D_{w, i}+\rho \Delta D+\gamma\left(\Delta r^{u}+\Delta r^{d}\right)\right]- \\
& \lambda\left(\sum_{i=1}^{N} G_{i}+P_{w, i}-\sum_{i=1}^{N} D_{i}\right)-\sigma\left(\sum_{i=1}^{N} D_{i}+\Delta D-\sum_{i=1}^{N} D_{i}^{0}\right)-\left(\sum_{i=1}^{N} \tau_{i}^{\min } D_{i}\right)- \\
& \left(\sum_{i=1}^{N} \tau_{i}^{\max }\left(D_{i}^{0}-D_{i}\right)\right)-\sum_{l=1}^{M} \mu_{l}^{\max }\left(L U_{l}-\sum_{i=1}^{N} G S F_{l-i}\left(G_{i}+P_{w, i}-D_{i}\right)\right)- \\
& \sum_{l=1}^{M} \mu_{l}^{\min }\left(L D_{l}+\sum_{i=1}^{N} G S F_{l-i}\left(G_{i}+P_{w, i}-D_{i}\right)\right)-\sum_{i=1}^{N} \omega_{i}^{\max }\left(G_{i}^{\max }-G_{i}-\right. \\
& \left.F R U_{i}\right)-\sum_{i=1}^{N} \omega_{i}^{\min }\left(G_{i}-F R D_{i}-G_{i}^{\min }\right)-\sum_{i=1}^{N} \varphi_{i}^{\max }\left(P_{w, i}^{\max }-P_{w, i}-\right. \\
& \left.F R U_{w, i}\right)-\sum_{i=1}^{N} \varphi_{i}^{\min }\left(P_{w, i}-F R D_{w, i}\right)-\sum_{i=1}^{N} \theta_{i}^{\max }\left(P_{w, i}^{r t}-P_{w, i}\right)- \\
& \sum_{i=1}^{N} \theta_{i}^{\min }\left(P_{w, i}\right)-\sum_{i=1}^{N} \vartheta_{i}^{u}\left(R R_{i}^{u}-F R U_{i}\right)-\sum_{i=1}^{N} \vartheta_{i}^{d}\left(R R_{i}^{d}-F R D_{i}\right)- \\
& \alpha\left(\sum_{i=1}^{N}\left(F R U_{i}+F R U_{w, i}\right)+\Delta r^{u}-F R U R\right)-\beta\left(\sum_{i=1}^{N}\left(F R D_{i}+F R D_{w,}\right)+\Delta r^{d}-\right. \\
& F R D R)-\left(\sum_{i=1}^{N} \delta_{i}^{u} F R U_{i}\right)-\left(\sum_{i=1}^{N} \delta_{i}^{d} F R D_{i}\right)-\left(\sum_{i=1}^{N} \delta_{w, i}^{u} F R U_{w, i}\right)- \\
& \left(\sum_{i=1}^{N} \delta_{w, i}^{d} F R D_{w, i}\right)-\varepsilon^{u} \Delta r^{u}-\varepsilon^{d} \Delta r^{d}, \\
& \pi_{i}=\lambda+\sum_{l=1}^{M} G S F_{l-i}\left(\mu_{l}^{\min }-\mu_{l}^{\max }\right),
\end{aligned}
$$

where (9) is the objective function of the ISO to minimize the total generation procurement cost, load-shedding cost, and ramping shortage penalty cost; (10) and (11) are the real-time demand and generation balance equations; (12) represents the demand limitation; (13) is the transmission constraints; (14) and (15) are the generation limitations considering flexible ramping products; (16) and (17) are the wind power limitations considering wind power providing flexible ramping products; (18) is the wind power limit; (19), (20), (23) and (24) are the limitations on the generation's flexible ramp products; (21) and (22) are the system's flexible ramping product requirement constraints; and (25) is the ramp shortage limitation. The variables on the right side of the colons are the dual variables associated with the corresponding equality or inequality constraints.

The LMP $\pi_{i}$ can be obtained from the dual variables of the optimal solution of the ISO's economic dispatch (ED). The Lagrangian function is in (26), and the LMP formulation is in (27).

\subsection{Mathematical Program with Equilibrium Constraints}

Given that the lower level problem is a linear programming problem, we transformed the bi-level strategic offering model into an MPEC by recasting the lower level problem to Karush-Kuhn-Tucker (KKT) optimality conditions [23-26], and then adding them into the upper level problem as a set of additional complementarity constraints.

$$
\text { Maximize (8), }
$$

s.t. Constraint in (10), (11), (21) and (22),

$$
\begin{gathered}
c_{i}-\lambda-\sum_{l=1}^{M} G S F_{l-i}\left(\mu_{l}^{\min }-\mu_{l}^{\max }\right)+\omega_{i}^{\max }-\omega_{i}^{\min }=0, \\
c_{i}^{w}-\lambda-\sum_{l=1}^{M} G S F_{l-i}\left(\mu_{l}^{\min }-\mu_{l}^{\max }\right)+\varphi_{i}^{\max }-\varphi_{i}^{\min }+\theta_{i}^{\max }-\theta_{i}^{\min }=0, \\
\rho-\sigma=0, \\
\gamma-\alpha-\varepsilon^{u}=0, \\
\gamma-\beta-\varepsilon^{d}=0, \\
\lambda-\sigma-\sum_{l=1}^{M} G S F_{l-i}\left(\mu_{l}^{\max }-\mu_{l}^{\min }\right)+\tau_{i}^{\max }-\tau_{i}^{\text {min }}=0, \\
\omega_{i}^{\max }+\vartheta_{i}^{u}-\alpha-\delta_{i}^{u}=0, \\
\omega_{i}^{\min }+\vartheta_{i}^{d}-\beta-\delta_{i}^{d}=0, \\
c_{u, i}^{w}+\varphi_{i}^{\max }-\alpha-\delta_{w, i}^{u}=0,
\end{gathered}
$$




$$
\begin{gathered}
c_{d, i}^{w}+\varphi_{i}^{\text {min }}-\beta-\delta_{w, i}^{d}=0, \\
0 \leq \tau_{i}^{\text {min }} \perp D_{i} \geq 0, \\
0 \leq \tau_{i}^{\text {max }} \perp D_{i}^{0}-D_{i} \geq 0, \\
0 \leq \mu_{l}^{\text {min }} \perp L D_{l}+\sum_{i=1}^{N} G S F_{l-i}\left(G_{i}+P_{w, i}-D_{i}\right) \geq 0, \\
0 \leq \mu_{l}^{\max } \perp L U_{l}-\sum_{i=1}^{N} G S F_{l-i}\left(G_{i}+P_{w, i}-D_{i}\right) \geq 0, \\
0 \leq \omega_{i}^{\text {min }} \perp G_{i}-F R D_{i}-G_{i}^{\text {min }} \geq 0, \\
0 \leq \omega_{i}^{\text {max }} \perp G_{i}^{\text {max }}-G_{i}-F R U_{i} \geq 0, \\
0 \leq \varphi_{i}^{\text {min }} \perp P_{w, i}-F R D_{w, i} \geq 0, \\
0 \leq \varphi_{i}^{\text {max }} \perp P_{w, i}^{r t+1}-P_{w, i}-F R U_{w, i} \geq 0, \\
0 \leq \theta_{i}^{\text {min }} \perp P_{w, i} \geq 0, \\
0 \leq \theta_{i}^{\text {max }} \perp P_{w, i}^{r t}-P_{w, i} \geq 0, \\
0 \leq \vartheta_{i}^{u} \perp R R_{i}^{u}-F R U_{i} \geq 0, \\
0 \leq \vartheta_{i}^{d} \perp R R_{i}^{d}-F R D_{i} \geq 0, \\
0 \leq \delta_{i}^{u} \perp F R U_{i} \geq 0, \\
0 \leq \delta_{i, t}^{d} \perp F R D_{i} \geq 0, \\
0 \leq \delta_{w, i}^{u} \perp F R U_{w, i} \geq 0, \\
0 \leq \delta_{w, i}^{d} \perp F R D_{w, i} \geq 0, \\
0 \leq \varepsilon^{u} \perp \Delta r^{u} \geq 0, \\
0 \leq \varepsilon^{d} \perp \Delta r^{d} \geq 0 .
\end{gathered}
$$

\subsection{Mixed-Integer Linear Programming}

The objective (8) of the MPEC is nonlinear because of the product terms, $\pi_{i} P_{w, i}, \alpha F R U_{w, i}$, and $\beta F R D_{w, i}\left(\pi_{i}, t, P_{w, i}, \alpha, F R U_{w, i}, \beta\right.$, and $F R D_{w, i}$ are variables) in the objective function and the complementarity constraints (40)-(57).

According to the strong duality theory, the objective of the primal problem is equal to the objective of the corresponding dual problem. For the RTED problem, the relationship between the objectives of the dual and primal problems can be expressed as follows:

$$
\begin{aligned}
& \sum_{i=1}^{N}\left[c_{i} G_{i}+c_{i}^{w} P_{w, i}+c_{u, i}^{w} F R U_{w, i}+c_{d, i}^{w} F R D_{w, i}+\rho \Delta D+\gamma\left(\Delta r^{u}+\Delta r^{d}\right)\right]=\sigma \sum_{i=1}^{N} D_{i}^{0}+ \\
& \sum_{i=1}^{N} \tau_{i}^{\max }\left(-D_{i}^{0}\right)+\sum_{l=1}^{M} \mu_{l}^{\max }\left(-L U_{l}\right)+\sum_{l=1}^{M} \mu_{l}^{\min }\left(-L D_{l}\right)+\sum_{i=1}^{N} \omega_{i}^{\max }\left(-G_{i}^{\max }\right)+ \\
& \sum_{i=1}^{N} \omega_{i}^{\min }\left(G_{i}^{\min }\right)+\sum_{i=1}^{N} \varphi_{i}^{\max }\left(-P_{w, i}^{r t+1}\right)+\sum_{i=1}^{N} \theta_{i}^{\max }\left(-P_{w, i}^{r t}\right)+\sum_{i=1}^{N} \vartheta_{i}^{u}\left(-R R_{i}^{u}\right)+ \\
& \sum_{i=1}^{N} \vartheta_{i}^{d}\left(-R R_{i}^{d}\right)+\alpha F R U R+\beta F R D R .
\end{aligned}
$$

From Equations (31), (38), (39) and Equation (58), Equation (59) is reformulated as: 


$$
\begin{aligned}
& \sum_{i=1}^{N}\left[c_{i} G_{i}+\left(\pi_{i}-\varphi_{i}^{\max }+\varphi_{i}^{\min }-\theta_{i}^{\max }+\theta_{i}^{\min }\right) P_{w, i}+\left(-\varphi_{i}^{\max }+\alpha+\delta_{w, i}^{u}\right) F R U_{w, i}+\right. \\
& \left.\left(-\varphi_{i}^{\min }+\beta+\delta_{w, i}^{d}\right) F R D_{w, i}+\rho \Delta D+\gamma\left(\Delta r^{u}+\Delta r^{d}\right)\right]=\sigma \sum_{i=1}^{N} D_{i}^{0}+\sum_{i=1}^{N} \tau_{i}^{\max }\left(-D_{i}^{0}\right)+ \\
& \sum_{l=1}^{M} \mu_{l}^{\max }\left(L U_{l}\right)+\sum_{l=1}^{M} \mu_{l}^{\min }\left(L D_{l}\right)+\sum_{i=1}^{N} \omega_{i}^{\max }\left(-G_{i}^{\max }\right)+\sum_{i=1}^{N} \omega_{i}^{\min }\left(G_{i}^{\min }\right)+ \\
& \sum_{i=1}^{N} \omega_{i}^{\min }\left(G_{i}^{\min }\right)+\sum_{i=1}^{N} \varphi_{i}^{\max }\left(-P_{w, i}^{r t+1}\right)+\sum_{i=1}^{N} \theta_{i}^{\max }\left(-P_{w, i}^{r t}\right)+\sum_{i=1}^{N} \vartheta_{i}^{u}\left(-R R_{i}^{u}\right)+ \\
& \alpha F R U R+\beta F R D R .
\end{aligned}
$$

Define B as:

$$
\begin{aligned}
B= & \sigma \sum_{i=1}^{N} D_{i}^{0}+\sum_{i=1}^{N} \tau_{i}^{\max }\left(-D_{i}^{0}\right) \\
& +\sum_{l=1}^{M} \mu_{l}^{\max }\left(-L U_{l}\right) \\
& +\sum_{l=1}^{M} \mu_{l}^{\min }\left(-L U_{l}\right) \\
& +\sum_{i=1}^{N} \omega_{i}^{\max }\left(-G_{i}^{\max }\right)+\sum_{i=1}^{N} \omega_{i}^{\min }\left(-G_{i}^{\min }\right) \\
& +\sum_{i=1}^{N} \varphi_{i}^{\max }\left(-P_{w, i}^{r t+1}\right)+\sum_{i=1}^{N} \theta_{i}^{\max }\left(-P_{w, i}^{r t}\right) \\
& +\sum_{i=1}^{N} \vartheta_{i}^{u}\left(-R R_{i}^{u}\right)+\sum_{i=1}^{N} \vartheta_{i}^{d}\left(-R R_{i}^{d}\right)+\alpha F R U R+\beta F R D R .
\end{aligned}
$$

Then

$$
\begin{aligned}
& \sum_{i \in A}\left[\left(\pi_{i}-\varphi_{i}^{\max }+\varphi_{i}^{\min }-\theta_{i}^{\max }+\theta_{i}^{\min }\right) P_{w, i}+\left(-\varphi_{i}^{\max }+\alpha+\delta_{w, i}^{u}\right) F R U_{w, i}+\right. \\
& \left.\left(-\varphi_{i}^{\min }+\beta+\delta_{w, i}^{d}\right) F R D_{w, i}\right]=B-\sum_{i=1}^{N}\left[c_{i} G_{i}+\rho \Delta D+\gamma\left(\Delta r^{u}+\Delta r^{d}\right)\right] .
\end{aligned}
$$

Note that the right side of Equation (61) is a linear formulation. The complementarity relation in (46) to (54) and (55) is used:

$$
\begin{gathered}
\varphi_{i}^{\max } P_{w, i}=\varphi_{i}^{\max }\left(P_{w, i}^{r t+1}-F R U_{w, i}\right), \\
\varphi_{i}^{\min } P_{w, i}=\varphi_{i}^{\min } F R D_{w, i}, \\
\theta_{i}^{\min } P_{w, i}=0, \\
\theta_{i}^{\max } P_{w, i}=\theta_{i}^{\max } P_{w, i}^{r t} \\
\delta_{w, i}^{u} F R U_{w, i}=0, \\
\delta_{w, i}^{d} F R D_{w, i}=0 .
\end{gathered}
$$

Combine Equation (62) to (67) with (61), then

$$
\begin{gathered}
\sum_{i \in A}\left[\pi_{i} P_{w, i}+\alpha F R U_{w, i}+\beta F R D_{w, i}\right]=\sum_{i \in A}\left(\varphi_{i}^{\max } P_{w, i}^{r t+1}+\theta_{i}^{\max } P_{w, i}^{r t}\right)+B- \\
\sum_{i=1}^{N}\left[c_{i} G_{i}+\rho \Delta D+\gamma\left(\Delta r^{u}+\Delta r^{d}\right)\right] .
\end{gathered}
$$

So

$$
\begin{aligned}
& \sum_{i \in A}\left[\pi_{i} P_{w, i}+\alpha F R U_{w, i}+\beta F R D_{w, i}\right]=\sigma \sum_{i=1}^{N} D_{i}^{0}+\sum_{i=1}^{N} \tau_{i}^{\max }\left(-D_{i}^{0}\right)+ \\
& \sum_{l=1}^{M} \mu_{l}^{\max }\left(-L U_{l}\right)+\sum_{l=1}^{M} \mu_{l}^{\min }\left(-L D_{l}\right)+\sum_{i=1}^{N} \omega_{i}^{\max }\left(-G_{i}^{\max }\right)+\sum_{i=1}^{N} \omega_{i}^{\min }\left(G_{i}^{\min }\right)+ \\
& \sum_{i=1}^{N} \vartheta_{i}^{u}\left(-R R_{i}^{u}\right)+\sum_{i=1}^{N} \vartheta_{i}^{d}\left(-R R_{i}^{d}\right)+\alpha F R U R+\beta F R D R-\sum_{i=1}^{N}\left[c_{i} G_{i}+\rho \Delta D+\right. \\
& \left.\gamma\left(\Delta r^{u}+\Delta r^{d}\right)\right] .
\end{aligned}
$$

The left side is the objective function of the wind power producer's strategic offering problem shown in Equation (5). In addition, the right side is a linear formulation. 
The complementarity constraints in model (40)-(57) are linearized using the Fortuny-Amat transformation [27]. Finally, the bi-level strategic offering problem is transformed into a MILP problem, as

Maximize (69),

$$
\begin{aligned}
& \text { s.t. Constraint (29) to (39) } \\
& 0 \leq D_{i} \leq M_{\tau}\left(1-v_{\tau, i}^{\min }\right) \text {, } \\
& 0 \leq \tau_{i}^{\min } \leq M_{\tau} v_{\tau, i}^{\min }, \\
& 0 \leq D_{i}^{0}-D_{i} \leq M_{\tau}\left(1-v_{\tau, i}^{\max }\right), \\
& 0 \leq \tau_{i}^{\max } \leq M_{\tau} v_{\tau, i}^{\max }\left(1-v_{\tau, i}^{\max }\right), \\
& 0 \leq \mu_{l}^{\min } \leq M_{\mu, l}^{\min } v_{\mu, l}^{\min }, \\
& 0 \leq L D_{l}+\sum_{i=1}^{N} G S F_{l-i}\left(G_{i}+P_{w, i}-D_{i}\right) \leq M_{\mu, l}^{\min }\left(1-v_{\mu, l}^{\min }\right), \\
& 0 \leq \mu_{l}^{\max } \leq M_{\mu, l}^{\max } v_{\mu, l}^{\max }, \\
& 0 \leq L U_{l}-\sum_{i=1}^{N} G S F_{l-i}\left(G_{i}+P_{w, i}-D_{i}\right) \leq M_{\mu, l}^{\max }\left(1-v_{\mu, l}^{\max }\right), \\
& 0 \leq \omega_{i}^{\min } \leq M_{\omega}^{\min } v_{\omega, i}^{\min }, \\
& 0 \leq G_{i}-F R D_{i}-G_{i}^{\min } \leq M_{\omega}^{\min }\left(1-v_{\omega, i}^{\min }\right), \\
& 0 \leq \omega_{i}^{\max } \leq M_{\omega}^{\max } v_{\omega, i}^{\max }, \\
& 0 \leq G_{i}^{\max }-G_{i}-F R U_{i} \leq M_{\omega}^{\max }\left(1-v_{\omega, i}^{\max }\right), \\
& 0 \leq \varphi_{i}^{\min } \leq M_{\varphi}^{\min } v_{\varphi, i}^{\min }, \\
& 0 \leq P_{w, i}-F R D_{w, i} \leq M_{\varphi}^{\min }\left(1-v_{\varphi, i}^{\min }\right), \\
& 0 \leq \varphi_{i}^{\max } \leq M_{\varphi}^{\max } v_{\varphi, i}^{\max }, \\
& 0 \leq P_{w, i}^{r t+1}-P_{w, i}-F R U_{w, i} \leq M_{\varphi}^{\max }\left(1-v_{\varphi, i}^{\max }\right), \\
& 0 \leq \theta_{i}^{\min } \leq M_{\theta}^{\min } v_{\theta, i}^{\min }, \\
& 0 \leq P_{w, i} \leq M_{\theta}^{\min }\left(1-v_{\theta, i}^{\min }\right), \\
& 0 \leq \theta_{i}^{\max } \leq M_{\theta}^{\max } v_{\theta, i}^{\max }, \\
& 0 \leq P_{w, i}^{r t}-P_{w, i} \leq M_{\theta}^{\max }\left(1-v_{\theta, i}^{\max }\right), \\
& 0 \leq \vartheta_{i}^{u} \leq M_{\vartheta}^{u} v_{\vartheta, i}^{u} \\
& 0 \leq R R_{i}^{u}-F R U_{i} \leq M_{\vartheta}^{u}\left(1-v_{\vartheta, i}^{u}\right) \text {, } \\
& 0 \leq \vartheta_{i}^{d} \leq M_{\vartheta}^{d} v_{\vartheta, i}^{d}, \\
& 0 \leq R R_{i}^{d}-F R D_{i} \leq M_{\vartheta}^{d}\left(1-v_{\vartheta, i}^{d}\right), \\
& 0 \leq F R U_{i} \leq M_{\delta}^{u}\left(1-v_{\delta, i}^{u}\right), \\
& 0 \leq \delta_{i}^{u} \leq M_{\delta}^{u} v_{\delta, i}^{u} \\
& 0 \leq F R D_{i} \leq M_{\delta}^{d}\left(1-v_{\delta, i}^{d}\right) \text {, }
\end{aligned}
$$




$$
\begin{gathered}
0 \leq \delta_{i}^{d} \leq M_{\delta}^{d} v_{\delta, i}^{d}, \\
0 \leq F R U_{w, i} \leq M_{\delta}^{w, u}\left(1-v_{\delta, i}^{w, u}\right), \\
0 \leq \delta_{w, i}^{u} \leq M_{\delta}^{w, u} v_{\delta, i}^{w, u}, \\
0 \leq F R D_{w, i} \leq M_{\delta}^{w, d}\left(1-v_{\delta, i}^{w, d}\right), \\
0 \leq \delta_{w, i}^{d} \leq M_{\delta}^{w, d} v_{\delta, i}^{w, d}, \\
0 \leq \varepsilon^{u} \leq M_{\varepsilon}^{u} v_{\varepsilon}^{u}, \\
0 \leq \Delta r^{u} \leq M_{\varepsilon}^{u}\left(1-v_{\varepsilon}^{u}\right), \\
0 \leq \varepsilon^{d} \leq M_{\varepsilon}^{d} v_{\varepsilon}^{d}, \\
0 \leq \Delta r^{d} \leq M_{\varepsilon}^{d}\left(1-v_{\varepsilon}^{d}\right),
\end{gathered}
$$

where $M_{\tau}, M_{\mu, l}^{\min }, M_{\mu, l}^{\max }, M_{\omega}^{\min }, M_{\omega}^{\max }, M_{\varphi}^{\min }, M_{\varphi}^{\max }, M_{\vartheta}^{u}, M_{\vartheta}^{d}, M_{\delta}^{u}, M_{\delta}^{d}, M_{\delta}^{w, u}, M_{\delta}^{w, d}, M_{\varepsilon}^{u}$, and $M_{\varepsilon}^{d}$ are large enough constants (typically 5000 10,000 in power system optimization), and $v_{\tau, i}^{\min }, v_{\tau, i}^{\max }, v_{\mu, l}^{\min }, v_{\mu, l}^{\max }$, $v_{\omega, i}^{\min }, v_{\omega, i}^{\max }, v_{\varphi, i}^{\min }, v_{\varphi, i}^{\max }, v_{\varphi, i}^{\min }, v_{\varphi, i}^{\max }, v_{\delta, i}^{u}, v_{\delta, i}^{d}, v_{\delta, i}^{w, u}, v_{\delta, i}^{w, d}, v_{\varepsilon}^{u}$, and $v_{\varepsilon}^{d}$ are the auxiliary binary variables [27-30].

The forecast uncertainty of other power plants offers can be modeled through a set of the probabilistic scenarios. Then, the model (70)-(107) can be integrated with a set of probabilistic scenarios and the model is transformed into a stochastic mixed integer linear programming model [18,26,31-33]. When there are multiple scenarios, the decomposition method can be utilized to solved this model [34].

\section{Case Studies}

The optimization was performed using the General Algebraic Modeling System (GAMS) [35], and the proposed strategic offering approach was tested on a modified PJM 5-bus system [17]. Figure 2 depicts the system.

The peak load is $1050 \mathrm{MW}$, which is equally distributed among buses B, C, and D. The ramp capability of every generator is $10 \mathrm{MW} / 5 \mathrm{~min} ; 5 \mathrm{~min}$ is the real-time market dispatch interval. Therefore, the ramp-up and ramp-down limits of traditional generators are both $10 \mathrm{MW}$ for the analysis in this study. The wind power plant is connected to Bus D. The real-time wind power and wind ramp forecasts are listed in Table 1.

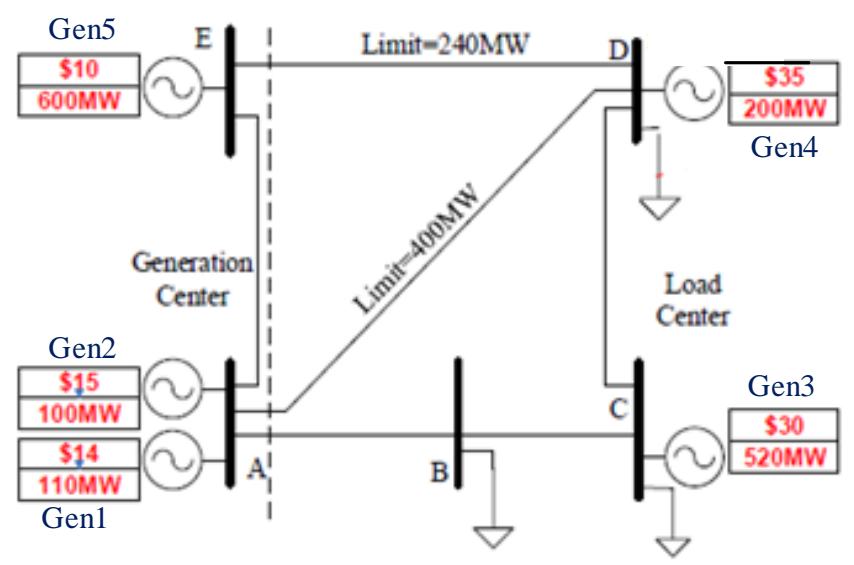

Figure 2. PJM 5-bus system and generation parameters. 
Table 1. Flexible ramp parameters of four cases.

\begin{tabular}{ccccc}
\hline Cases & FRUR $(\mathbf{M W})$ & FRDR $(\mathbf{M W})$ & $\boldsymbol{P}_{\boldsymbol{w}, \boldsymbol{i}}^{r t}(\mathbf{M W})$ & $\boldsymbol{P}_{\boldsymbol{w}, \boldsymbol{i}}^{r t+\mathbf{1}}(\mathbf{M W})$ \\
\hline Case 1 & 70 & 10 & 180 & 185 \\
Case 2 & 70 & 10 & 180 & 175 \\
Case 3 & 10 & 70 & 180 & 185 \\
Case 4 & 10 & 70 & 180 & 175 \\
\hline
\end{tabular}

\subsection{Wind Ramp and Demand Ramp Coordination}

In this subsection, the four cases shown in Figure 3 are studied to analyze the impact of wind power to provide flexible ramping products. The ramping requirements of the four cases are listed in Table 1.

Case 1: Wind up-ramp with load up-ramp

Case 2: Wind down-ramp with load up-ramp

Case 3: Wind up-ramp with load down-ramp

Case 4: Wind down-ramp with load down-ramp.

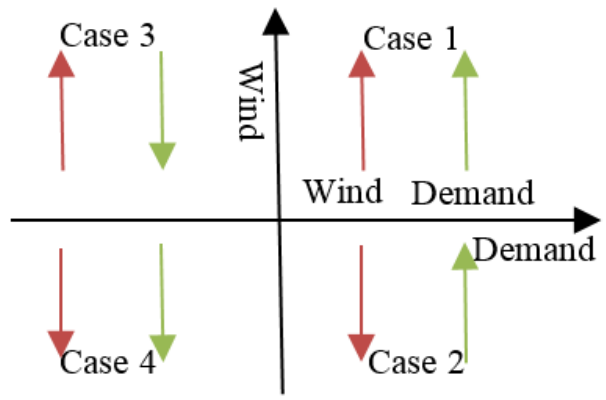

Figure 3. Four wind and demand ramp scenarios.

In this study, the wind offer price for both the flexible ramp-up and ramp-down products are fixed to 0 . The opportunity cost and the offer price for the ramp products associated with wind are analyzed in the next subsections. The wind power dispatch results including the dispatched power and flexible ramps are shown in Table 2, and the clearing prices and profits are listed in Table 3. The results in Tables 2 and 3 are obtained from the proposed model in (24). In Table 3, the LMP is the price at Bus D to which the wind power plant is connected.

Table 2. Wind offer results of four cases.

\begin{tabular}{cccc}
\hline Cases & $\boldsymbol{P}_{\boldsymbol{W}, \boldsymbol{i}} \mathbf{( M W )}$ & $\boldsymbol{F R U _ { W }} \mathbf{( M W )}$ & $\mathbf{F R U}_{\mathbf{w}}(\mathbf{M W})$ \\
\hline Case 1 & 165 & 20 & 0 \\
Case 2 & 155 & 20 & 0 \\
Case 3 & 180 & 0 & 70 \\
Case 4 & 180 & 0 & 70 \\
\hline
\end{tabular}

Table 3. Wind price and profit results of the four cases.

\begin{tabular}{cccccc}
\hline Cases & $\boldsymbol{\pi} \mathbf{( \$ \mathbf { M W } ) @ \text { Bus D }}$ & $\boldsymbol{\alpha} \mathbf{( \$ \mathbf { M W } )}$ & $\boldsymbol{\beta} \mathbf{( \$ \mathbf { M W } )}$ & Profit (\$) & Comp. Time (s) \\
\hline Case 1 & 30 & 30 & 0 & 5550 & 0.81 \\
Case 2 & 30 & 30 & 0 & 5250 & 0.74 \\
Case 3 & 35 & 0 & 0 & 6300 & 0.83 \\
Case 4 & 35 & 0 & 0 & 6300 & 0.92 \\
\hline
\end{tabular}


Table 2 shows that when both the wind and the load ramp up in Case 1, the wind ramp can provide some of the ramp-up requirement. Therefore, the wind curtailment is lower in Case 1 than that in Case 2. When the system has a higher ramp-down requirement in Case 3 and Case 4, wind power can provide the ramp-down requirement.

In this study, the wind ramp product offer prices are 0 , so the system has no additional cost with wind providing the ramp product. As shown in Table 3, when wind power curtails its output to provide the ramp-up, the price for the ramp-up product is the same as the energy LMP. When wind provides the ramp-down product, the ramp-down price is still 0 , which means that the system has no additional cost associated with wind providing the ramp-down product; however, there is an opportunity cost for wind providing the ramping product. This is analyzed in the next subsection.

\subsection{Opportunity Cost for Wind Providing Ramp Products}

In Case 1 and Case 2, the prices for wind providing energy and the ramp-up product are the same. Therefore, when wind curtails the power output to provide the ramp-up product, it will receive the same amount of revenues from providing the ramp-up product. In current markets, wind power will receive some subsidies for its power production, like emission free credits. Therefore, the opportunity cost for providing the ramp-up product with wind curtailment included the lost subsidies.

For instance, if there is a subsidy of $\$ 5 / \mathrm{MW}$ for wind power, in Case 1 the opportunity cost of the curtailed $15 \mathrm{MW}$ of wind power would be $\$ 5 \times 15=\$ 75$ in which $\$ 5$ is the subsidy price. Although, some markets have a higher subsidy price for wind, this subsidy is prone to decline due to the cost of wind decreasing. Because the wind power is forecasted to ramp up in the next interval, the $5 \mathrm{MW}$ wind ramp-up (185-180 MW) will lead to a revenue of $\$ 30 \times 5=\$ 150$ from providing the ramp-up product. The opportunity cost would be $\$ 75-\$ 150=-\$ 75$, which means there is a net-profit for wind by providing the ramp-up product. Therefore, when both wind and load ramp up, wind power can lead to more money being earned by providing the ramp-up product, even if it commits more capacity towards the ramping-up product (under the given cost and subsidy assumptions). In Case 2, because wind power is forecasted to ramp down in the next interval, the wind curtails $25 \mathrm{MW}$ to provide a $20 \mathrm{MW}$ ramp-up capability for the system's next interval ramp-up requirement. The opportunity cost is $\$(30+5) \times 25-\$ 20 \times 30=\$ 275$, meaning wind would lose money for providing the ramp-up product in this case.

However, the opportunity cost to provide the ramp-down product is not as intuitive as that of the ramp-up product. In Case 3 and Case 4, the wind still generates the maximum available power at current interval to provide the ramp-down product. But in the next interval, the wind power output should ramp down. For instance, in Case 3, wind should hold the power output at $110 \mathrm{MW}$ (180 MW - $70 \mathrm{MW}$ ) for the next interval. Therefore, if wind has an available power output of more than $110 \mathrm{MW}$ in the next interval, there will be a curtailment loss for wind in the next interval. Then, the opportunity cost is like that of the ramp-up product. In Case 3, the wind curtailment for the next interval is $75 \mathrm{MW}(185 \mathrm{MW}-110 \mathrm{MW})$. In Case 4, the curtailment is $65 \mathrm{MW}(175 \mathrm{MW}-110 \mathrm{MW})$. The price for the ramp-down product is 0 , which means that there is no revenue for providing the ramp-down product. So, the opportunity cost is $75 \mathrm{MW}$ multiplied by the LMP in the next interval plus the subsidy price. Therefore, when both wind and load ramp down, the opportunity cost for wind providing the ramp-down product is less than it is when the wind ramps up and the load ramps down because the potential wind curtailment is lower in the former case.

For both the ramp-up and ramp-down products, when the wind ramp direction coincides with the load ramp direction, the opportunity cost for wind providing the ramp products is less than that when the wind ramp direction is opposite of the load ramp direction.

\subsection{Ramp Price for Wind Ramping Products}

In this subsection, wind offer prices for ramp products are developed, such that wind can recover the opportunity cost and participate more actively in the ramp market. 
In Case 1, when the wind ramps up, the total revenue to provide the ramp-up product can be formulated as

$$
R_{r u}=F R U\left(\pi+p_{r u}\right)-\left(F R U-\Delta P_{r u}\right)\left(\pi+p_{s}\right)>0,
$$

where $R_{r u}$ is the total profit for providing the ramp-up product; $\pi$ is the current interval energy LMP; $p_{r u}$ is the offer price for the ramp-up product; $\Delta P_{r u}$ is the wind forecast ramp-up capacity; $p_{s}$ is the subsidy price received by wind for the energy; and $F R U$ is the total capacity for the ramp-up product provided by the wind.

Then, when

$$
p_{r u}>p_{s}-\frac{\Delta P_{r u}}{F R U}\left(\pi+p_{s}\right),
$$

wind power can earn a positive profit through providing a ramp-up product.

In Case 2, when the wind ramps down, the total revenue is

$$
R_{r u}=F R U\left(\pi+p_{r u}\right)-\left(F R U+\Delta P_{r d}\right)\left(\pi+p_{s}\right)>0,
$$

where $\Delta P_{r d}$ is the wind forecast ramp-down capacity.

Then, when

$$
p_{r u}>p_{s}+\frac{\Delta P_{r d}}{F R U}\left(\pi+p_{s}\right),
$$

wind power can earn a positive profit by providing the ramp-up product.

For the ramp-up product, because the potential opportunity cost is caused by the wind curtailment at the current time interval, and because this cost is already included in the objective function in (5), if the ramp-up offer price is given by (109) or (111), the wind power opportunity cost for providing the ramp-up product can be recovered. Then, the strategic offering model can endogenously optimize the wind power output and the ramp-up capacity to maximize its profit.

For the ramp-down product, although the lower bound of the offer price can be formulated via a similar method as (109) and (111) in order to recover the opportunity cost in the next time interval, this can change the generation dispatch at the current time interval and lead to a suboptimal solution for wind power scheduling at the current interval. For instance, Table 4 shows the results with a fixed ramp-down offer price ( $\$ 40 / \mathrm{MW}$ for the ramp-down product) and without the fixed offer price for wind power (the lower limit is $\$ 0 / \mathrm{MW}$ for the ramp-down product). Figure 4 demonstrates the generation dispatch under the two scenarios.

Table 4 shows that although setting the ramp-down offer price can increase the clearing price for the ramp-down product, it also reduces the energy LMP, which leads to less total profit for the current time interval. When the ramp-down product offer price is 0 , the system can schedule more ramp-down capacity from wind power. Therefore, expensive generation, such as Gen4, is not scheduled. However, the generation dispatch shown in Figure 4 demonstrates that with this fixed $\$ 40 / \mathrm{MW}$ wind offer price for the ramp-down product, the expensive Gen4 increases its power output to provide the ramp-down product. The total ramp-down capability is $50 \mathrm{MW}$, but the ramp-down requirement is $70 \mathrm{MW}$. Therefore, the system LMP changes, and the wind power profit is less.

Table 4. Wind offer results of Cases 3 and 4.

\begin{tabular}{cccccccc}
\hline & Cases & $\boldsymbol{P}_{\boldsymbol{w}, \boldsymbol{i}}(\mathbf{M W})$ & $\boldsymbol{F R D _ { W }} \mathbf{( M W )}$ & $\boldsymbol{\pi} \mathbf{( \$ \mathbf { M W } )}$ & $\boldsymbol{\beta} \mathbf{( \$ \mathbf { M W } )}$ & Profit (\$) & Comp. Time (s) \\
\hline \multirow{2}{*}{ Fixed } & Case 3 & 180 & 20 & 20.358 & 40 & 4464.393 & 0.76 \\
& Case 4 & 180 & 20 & 20.358 & 40 & 4464.393 & 0.85 \\
\hline \multirow{2}{*}{ Not } & Case 3 & 180 & 30 & 35 & 0 & 6300 & 0.81 \\
Fixed & Case 4 & 180 & 30 & 35 & 0 & 6300 & 0.79 \\
\hline
\end{tabular}




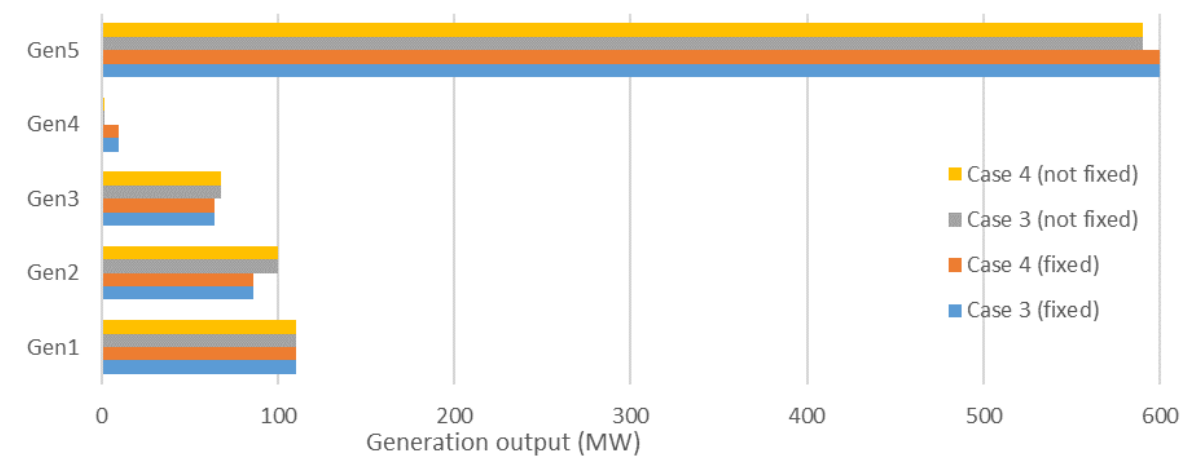

Figure 4. Generation dispatch with fixed and without fixed ramp-down product offer price.

The opportunity cost for the ramp-down product is the potential wind curtailment cost in the next time interval, which is not explicitly included in the objective function in (5).

In Case 3, when the wind ramps up while providing the ramp-down product, the revenue is

$$
R_{w}=\sum_{i \in A}\left[\pi_{i} P_{w, i}+\alpha F R U_{w, i}+\beta F R D_{w, i}-\left(F R D_{w, i}+\Delta P_{r u, w, i}\right) \times\left(\pi_{n e x t, i}+p_{s}\right)\right],
$$

where $\pi_{\text {next }}$ is the next interval energy LMP forecast value.

In Case 4 , the revenue is

$$
R_{w}=\sum_{i \in A}\left[\pi_{i} P_{w, i}+\alpha F R U_{w, i}+\beta F R D_{w, i}-\left(F R D_{w, i}-\Delta P_{r d, w, i}\right) \times\left(\pi_{n e x t, i}+p_{s}\right)\right] .
$$

With the objective function modeled in (112) and (113), when providing the ramp-down products, the wind can optimize its power and ramp-down capacity to maximize its profit at the current time interval. But, the opportunity cost for providing the ramp-down product is still not recovered in this objective function. To compensate for the wind power's service of the ramp-down capacity and to maintain market efficiency, some out-of-market measurements should be provided.

Note that $\pi, \pi_{\text {next }}, F R U$, and FRD are the ISO's economic dispatch results, which means that the wind power producer will not know the exact values of these variables before the strategic offer model is solved. Therefore, they should offer the ramp-up product prices based on the forecast of these variables from the historical data.

The wind dispatch with the ramp-up offer price lower limit and new objective function for the ramp-down product are shown in Tables 5 and 6. For Case 1, because the wind ramps up with the same load ramp direction, the ramp-up product price is still 0. For Case 2, the wind ramp-up price is $\$ 13.75 / \mathrm{MW}$, as shown in Equation (28). Therefore, the clearing price for the ramp-up product increases to $\$ 43.75 / \mathrm{MW}$, which recovers the opportunity cost of curtailing wind to provide the ramp-up product. For Case 3 and Case 4, compared to Tables 2 and 4, Table 5 shows that when considering the potential wind curtailment opportunity cost, the wind schedules less ramp-down capacity, and the clearing price for the ramp-down product increases. The increment for the ramp-down product price does not significantly reduce the energy LMP; therefore, the profit at the current interval is reduced only slightly. Considering the potential wind curtailment cost in the next time interval, in Case 3, the opportunity cost is $\$ 24.475 \times 40=\$ 974$, as shown in Table 5. Here $\$ 40 /$ MWh is the forecast LMP $\$ 35 /$ MWh in the next interval (from Tables 4 and 6 , this forecast is reasonable) plus the $\$ 5 /$ MWh subsidy. In Tables 2 and 4, the opportunity cost of providing the ramp-down product in Case 3 is $\$ 70 \times 40=\$ 2800$ and $\$ 30$ $\times 40=\$ 1200$ (Not fixed, Case 3 in Table 4), respectively. Obviously, the opportunity cost of providing the ramp-down product is reduced significantly in Table 5. As shown in Table 3, Table 4, and Table 6, all the cases can be solved within one second which demonstrates that the computational burden of the proposed model is not high. 
Table 5. Wind offer results of the four cases.

\begin{tabular}{|c|c|c|c|}
\hline Cases & $P_{W, i}(\mathrm{MW})$ & $F R U_{w}(\mathrm{MW})$ & $F R D_{w}(\mathrm{MW})$ \\
\hline Case 1 & 165 & 20 & 0 \\
\hline Case 2 & 155 & 20 & 0 \\
\hline Case 3 & 180 & 0 & 24.475 \\
\hline Case 4 & 180 & 0 & 24.475 \\
\hline
\end{tabular}

Table 6. Wind price and profit results of the four cases.

\begin{tabular}{|c|c|c|c|c|c|}
\hline Cases & $\pi(\$ / M W) @$ Bus D & $\alpha(\$ / M W)$ & $\beta(\$ / \mathbf{M W})$ & Profit (\$) & Comp. Time (s) \\
\hline Case 1 & 30 & 30 & 0 & 5550 & 0.73 \\
\hline Case 2 & 30 & 43.75 & 0 & 5525 & 0.82 \\
\hline Case 3 & 34.324 & 0 & 0.676 & 6194.872 & 0.81 \\
\hline Case 4 & 34.324 & 0 & 0.676 & 6194.872 & 0.77 \\
\hline
\end{tabular}

Figure 5 shows that the generation dispatch varies with the system's ramp requirement. Compared to the ramp-up requirement, in the ramp-down scenarios, such as Case 3 and Case 4, the expensive generators, such as Gen4, increase their power output to provide ramp-down capacity. Therefore, the ramping requirement changes the generation dispatch and the LMP. If there is a shortage in ramping resources, the dispatch and LMP will be distorted from the reasonable values.

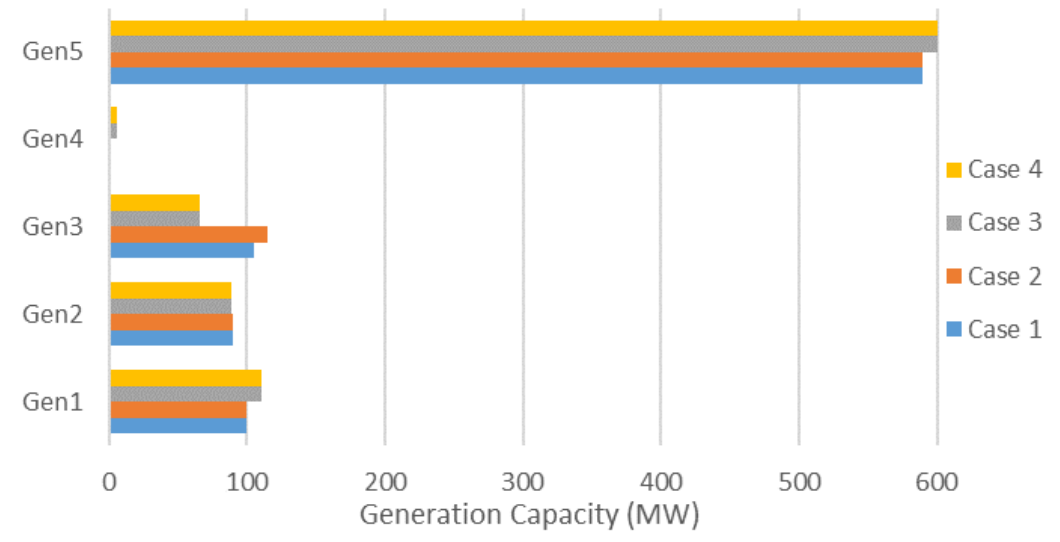

Figure 5. Generation dispatch with ramp-up product price and new objective function for ramp-down product.

\subsection{Impact of Wind Ramp Forecast}

The previous subsections showed that the wind power forecast for the next time interval is critical for scheduling both ramp-up and ramp-down products. This subsection analyzes the forecast uncertainty sensitivity on the wind power producer's profit. The case for wind providing the ramp-up product is studied.

If the next interval of wind power output is uncertain, the total revenue to provide the ramp-up product is formulated similarly to (108) and (110). Therefore, the revenue is

$$
\begin{aligned}
& R_{r u}=\int_{-\infty}^{+\infty}\left[F R U\left(\pi+p_{r u}\right)-\left(F R U+P_{w}^{r t}-x\right)\left(\pi+p_{s}\right)\right] f(x) d x, \\
& =\int_{-\infty}^{+\infty}\left[F R U \Delta\left(p_{r u}-p_{s}\right)-P_{w}^{r t}\left(\pi+p_{s}\right)\right] f(x) d x+\int_{-\infty}^{+\infty} x\left(\pi+p_{s}\right) f(x) d x, \\
& =F R U \Delta\left(p_{r u}-p_{s}\right)-P_{w}^{r t}\left(\pi+p_{s}\right)+\left(\pi+p_{s}\right) E(x) \geq 0,
\end{aligned}
$$

where $x$ is the probabilistic wind power output at the next time interval; and $f(x)$ and $E(x)$ are the probability density function and the expected value of the next time interval wind power output, respectively. 
Then

$$
p_{r u} \geq p_{s}+\frac{\left[P_{w}^{r t}-E(x)\right]\left(\pi+p_{s}\right)}{F R U}
$$

Therefore, (115) determines the ramp-up product offer price for wind power. It shows that the offer price is determined by the expected value of the next interval power output. If the expected power output of the next interval is higher than that of the current interval, the wind ramps up, and the offering price of the ramp-up product is less than the subsidy price. In contrast, if the expected power output in the next interval is less than that in the current interval, the wind ramps down, and the offering price of the ramp-up product is higher than the subsidy price.

\subsection{Case Study with Multiple Time Intervals}

In this subsection, a one-hour study with 12.5 min intervals for the wind power's strategic offering considering both the energy and flexible ramping products is performed. The hourly load curve and the wind forecast mean power curves are from CAISO at 6:00 a.m. on 2 January 2018 [36], as shown in Figure 6. The offering price for ramping up and down products are fixed to $\$ 7.5 / \mathrm{MW}$ and $\$ 15 / \mathrm{MW}$, respectively. The dispatched wind power and its ramping capacities are shown in Figure 7. In Figure 7, the wind available power and dispatched wind power are shown on the left axis and the ramping up/down products capacities are shown on the right axis. The LMPs for the energy provided by wind power and the clearing price for the ramping up/down products are shown in Figure 8.

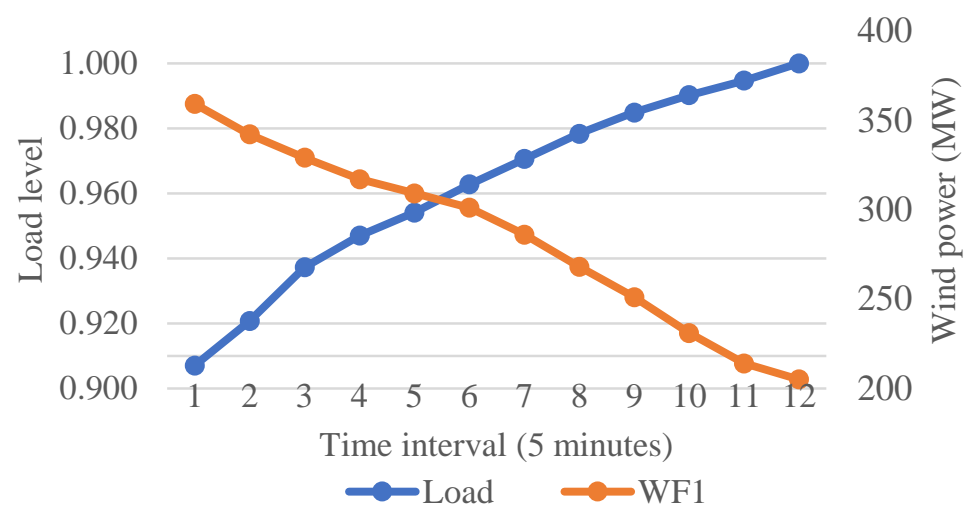

Figure 6. Wind and load curves.

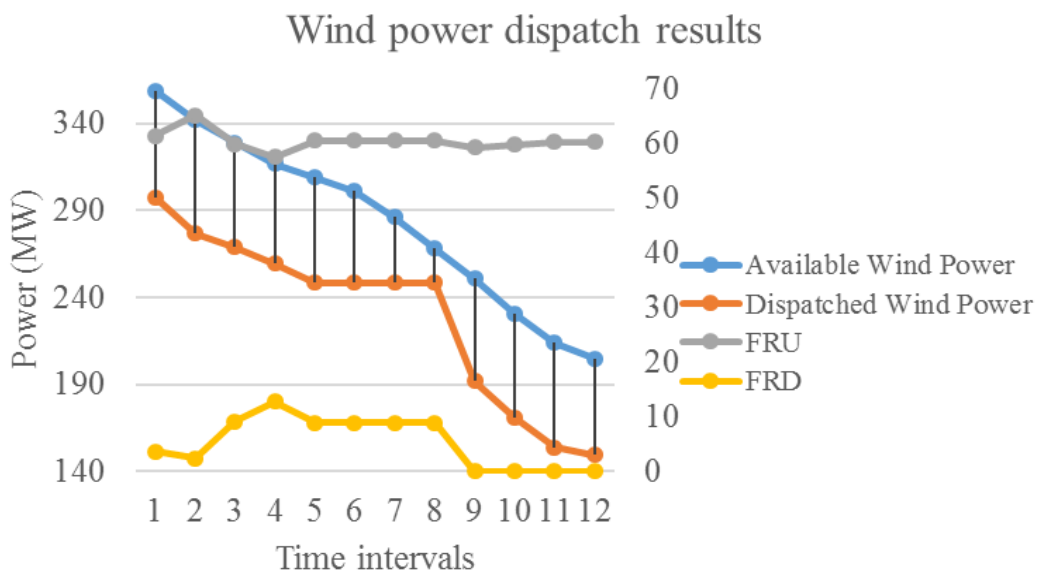

Figure 7. Dispatched wind power and the ramping products capacities.

In Figure 7, it is obvious that wind power curtails its power output to provide the ramping up product because its dispatched power is lower than the forecasted available wind power. In this case, 
the system ramping capacity from the traditional generators is lower than the ramping up requirement. Therefore, wind power should provide this ramping up service. In this scenario, the load is ramping up while the wind power is ramping down. Therefore, the opportunity cost for wind power to provide the ramping up product is higher than the wind subsidy prices shown in Equation (32).

Figure 8 shows that when the wind power offers a ramping up product price, the final clearing price for the ramping up product is the LMP for energy plus the offering price of the ramping up product. Therefore, through this offering price for the ramping up product, the opportunity cost can be recovered. For the ramping down product, during the 9th to 12th intervals, the clearing price is 0 . Therefore, wind power does not provide the ramping down product in this period, as shown in Figure 7.

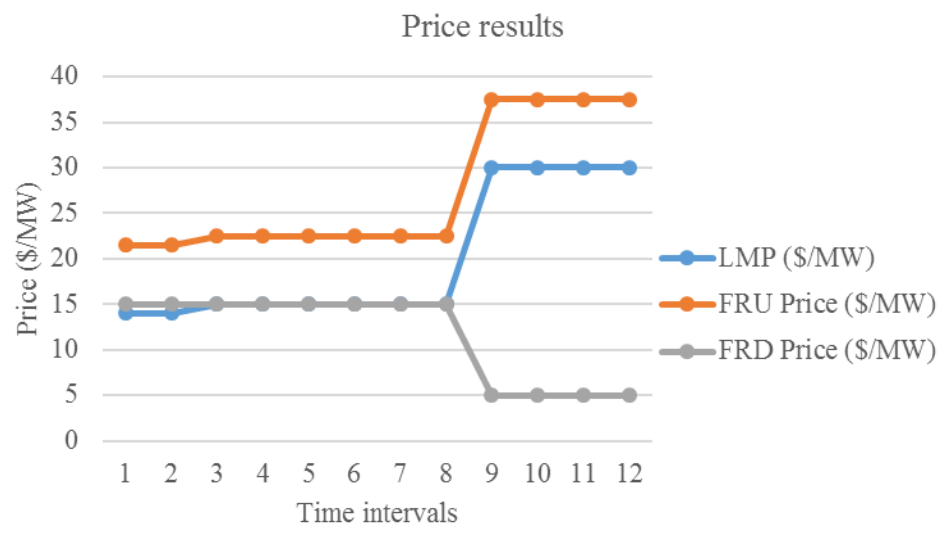

Figure 8. Locational marginal prices (LMPs) for energy and the ramping up/down products prices for wind power producer.

\section{Conclusions}

This paper proposed a strategic offering model for wind power providing both energy and flexible ramping products. The main contributions of the proposed model can be summarized as:

1. The joint energy and flexible ramping product offering model for wind power in the real-time market is proposed and transformed into a solvable MILP model which can be efficiently solved.

2. The opportunity cost associated with wind providing ramping products is analyzed. When the ramp direction of wind coincides with the system load ramp direction, the opportunity cost is lower.

3. When wind provides the ramp-up product, it can recover the opportunity cost of providing the ramp-up product with wind curtailment through an offer price for the ramp-up product.

4. When providing the ramp-down product, this opportunity cost cannot be explicitly recovered, and some out-of-market measurement is needed to recover the wind power's opportunity cost to provide the ramp-down product.

5. The wind power forecast uncertainty has a significant impact on the offering price for ramping products. If the next interval wind forecast's mean value is higher than the current wind power output, the offering price for the ramp-up product is less than the subsidy price. Otherwise, it should be more than the subsidy price.

6. When the system is short of ramping up/down capacities, wind power has the market power to some degree. ISOs should have some measurements to mitigate this market power.

Future work will include studying the market designs to recover the wind power's opportunity cost to provide the ramp-down product. 
Author Contributions: Conceptualization, X.F. and V.K., and B.-M.H.; Methodology, X.F.; Software, X.F.; Validation, X.F., V.K., and B.-M.H.; Formal Analysis, X.F.; Investigation, X.F., B.-M.H.; Resources, X.F.; Data Curation, X.F.; Writing-Original Draft Preparation, X.F.; Writing-Review \& Editing, X.F., B.-M.H.; Visualization, X.F.; Supervision, B.-M.H.; Project Administration, B.-M.H.; Funding Acquisition, B.-M.H.

Acknowledgments: This work was authored by Alliance for Sustainable Energy, LLC, the Manager and Operator of the National Renewable Energy Laboratory for the U.S. Department of Energy (DOE) under Contract No. DE-AC36-08GO28308. Funding provided by U.S. Department of Energy Office of Energy Efficiency and Renewable Energy Wind Energy Technologies Office. The views expressed in the article do not necessarily represent the views of the DOE or the U.S. Government. The U.S. Government retains and the publisher, by accepting the article for publication, acknowledges that the U.S. Government retains a nonexclusive, paid-up, irrevocable, worldwide license to publish or reproduce the published form of this work, or allow others to do so, for U.S. Government purposes.

Conflicts of Interest: The authors declare no conflict of interest.

\section{Nomenclature}

Other variables are explained in the text

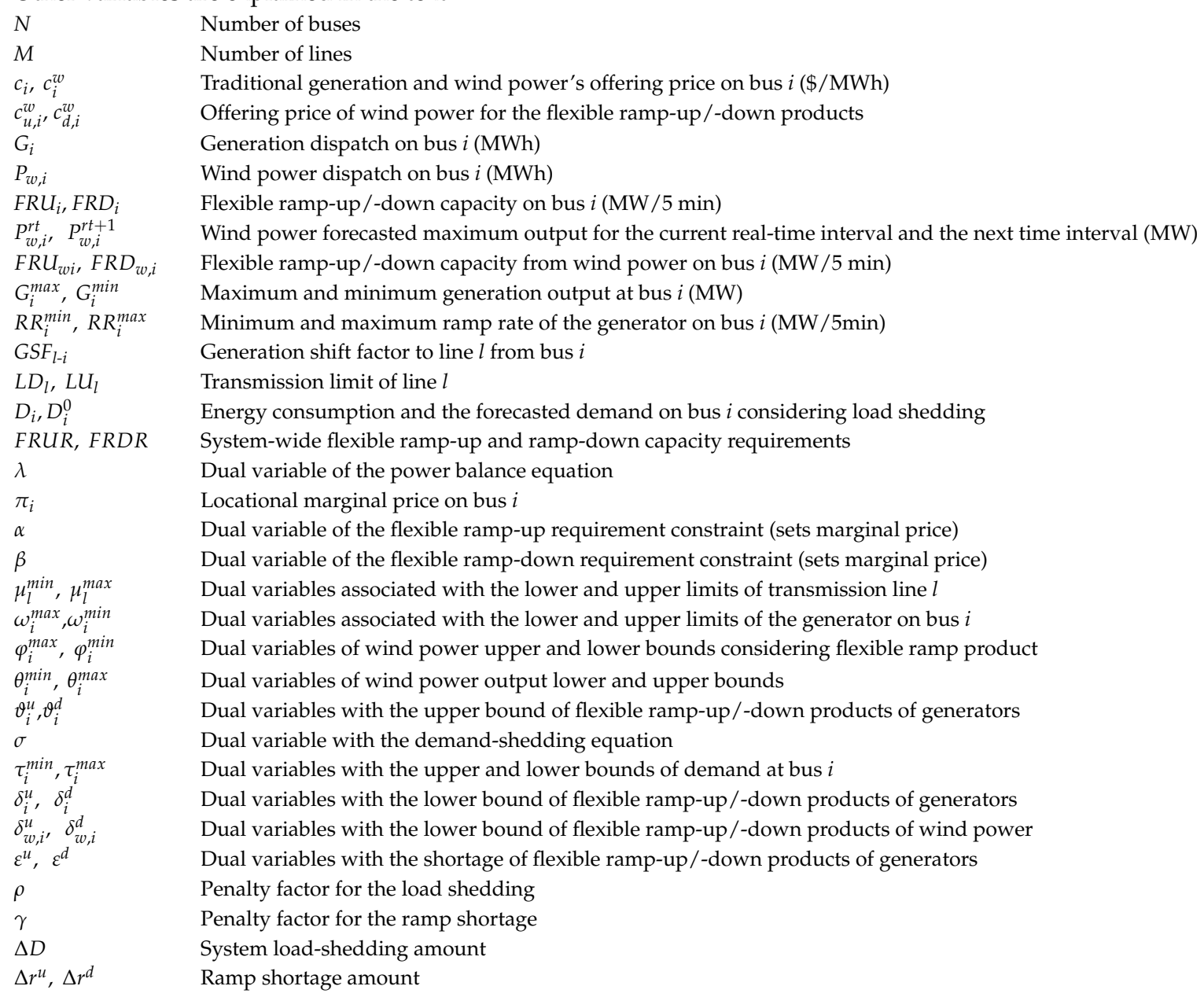

\section{References}

1. U.S. Department of Energy. Staff Report to the Secretary on Electricity Markets and Reliability; U.S. Department of Energy: Washington, DC, USA, August 2017.

2. Lannoye, E.; Flynn, D.; O’Malley, M. Evaluation of power system flexibility. IEEE Trans. Power Syst. 2012, 27, 922-931. [CrossRef]

3. Mei, S.; Zhang, D.; Wang, Y.; Liu, F.; Wei, W. Robust Optimization of static reserve planning with large-scale integration of wind power: A game theoretic approach. IEEE Trans. Sustain. Energy 2014, 5, 535-545. [CrossRef] 
4. He, G.; Chen, Q.; Kang, C.; Xia, Q. Optimal Offering Strategy for Concentrating Solar Power Plants in Joint Energy, Reserve and Regulation Markets. IEEE Trans. Sustain. Energy 2016, 7, 1245-1254. [CrossRef]

5. Chen, R.; Wang, J.; Botterud, A.; Sun, H. Wind Power Providing Flexible Ramp Product. IEEE Trans. Power Syst. 2017, 32, 2049-2061. [CrossRef]

6. California ISO. Flexible Ramping Products: Revised Draft Final Proposal; California ISO: Folsom, CA, USA, 17 December 2015; pp. 1-18.

7. Navid, N.; Rosenwald, G. Ramp Capability Product Design for MISO Markets; Midcontinent Independent System Operator: Saint Paul, MN, USA, 22 December 2013.

8. Cornelius, A. Assessing the Impact of Flexible Ramp Capacity Products in the Midcontinent ISO. Master's Thesis, Duke University, Durham, NC, USA, May 2014.

9. Cui, M.; Zhang, J.; Wu, H.; Hodge, B.M. Wind-Friendly Flexible Ramping Product Design in Multi-Timescale Power System Operations. IEEE Trans. Sustain. Energy 2017, 8, 1064-1075. [CrossRef]

10. Cui, M.; Zhang, J.; Feng, C.; Florita, A.R.; Sun, Y.; Hodge, B.M. Characterizing and analyzing ramping events in wind power, solar power, load, and netload. Renew. Energy 2017, 111, 227-244. [CrossRef]

11. Sevlian, R.; Rajagopal, R. Detection and statistics of wind power ramps. IEEE Trans. Power Syst. 2013, 28, 3610-3620. [CrossRef]

12. Wu, C.; Hug, G.; Member, S.; Kar, S. Risk-Limiting Economic Dispatch for Electricity Markets with Flexible Ramping Products. IEEE Trans. Power Syst. 2015, 31, 1990-2003. [CrossRef]

13. Zhang, B.; Kezunovic, M. Impact on Power System Flexibility by Electric Vehicle Participation in Ramp Market. IEEE Trans. Smart Grid 2016, 7, 1285-1294. [CrossRef]

14. Wang, B.; Hobbs, B.F. Real-Time Markets for Flexiramp: A Stochastic Unit Commitment-Based Analysis. IEEE Trans. Power Syst. 2016, 31, 846-860. [CrossRef]

15. Makarov, Y.V.; Loutan, C.; Ma, J.; de Mello, P. Operational impacts of wind generation on California power systems. IEEE Trans. Power Syst. 2009, 24, 1039-1050. [CrossRef]

16. Moiseeva, E.; Hesamzadeh, M.R.; Biggar, D.R. Exercise of Market Power on Ramp Rate in Wind-Integrated Power Systems. IEEE Trans. Power Syst. 2015, 30, 1614-1623. [CrossRef]

17. Fang, X.; Krishnan, V.; Hodge, B. Potential of Wind Power to Provide Flexible Ramping Products and Operating Reserve. In Proceedings of the IEEE PES General Meeting, Portland, OR, USA, 5-9 August 2018; pp. 1-5.

18. Baringo, L.; Conejo, A.J. Strategic offering for a wind power producer. IEEE Trans. Power Syst. 2013, 28, 4645-4654. [CrossRef]

19. Mahmoudi, N.; Saha, T.K.; Eghbal, M. Wind Power Offering Strategy in Day-Ahead Markets: Employing Demand Response in a Two-Stage Plan. IEEE Trans. Power Syst. 2014, 30, 1888-1896. [CrossRef]

20. Baringo, L.; Conejo, A.J. Offering Strategy of Wind-Power Producer: A Multi-Stage Risk-Constrained Approach. IEEE Trans. Power Syst. 2016, 31, 1420-1429. [CrossRef]

21. Heydarian-Forushani, E.; Moghaddam, M.P.; Sheikh-El-Eslami, M.K.; Shafie-Khah, M.; Catalao, J.P.S. Risk-constrained offering strategy of wind power producers considering intraday demand response exchange. IEEE Trans. Sustain. Energy 2014, 5, 1036-1047. [CrossRef]

22. Zhao, J.; Brereton, B.; Montalvo, M. Gaming-based reserve constraint penalty factor analysis. IEEE Trans. Power Syst. 2011, 26, 616-626. [CrossRef]

23. Hobbs, B.F.; Metzler, C.B.; Pang, J.-S. Strategic Gaming Analysis for Electric Power Systems: An MPEC Approach. IEEE Trans. Power Syst. 2006, 21, 143-152. [CrossRef]

24. Wogrin, S.; Centeno, E.; Barquin, J. Generation capacity expansion in liberalized electricity markets: A stochastic MPEC approach. IEEE Trans. Power Syst. 2011, 26, 2526-2532. [CrossRef]

25. Ruiz, C.; Conejo, A.J.; Smeers, Y. Equilibria in an oligopolistic electricity pool with stepwise offer curves. IEEE Trans. Power Syst. 2012, 27, 752-761. [CrossRef]

26. Fang, X.; Hu, Q.; Li, F.; Wang, B.; Li, Y. Coupon-Based Demand Response Considering Wind Power Uncertainty: A Strategic Bidding Model for Load Serving Entities. IEEE Trans. Power Syst. 2016, 31, 1025-1037. [CrossRef]

27. Fortuny-Amat, J.; McCarl, B. A Representation and Economic Interpretation of a Two-Level Programming Problem. J. Oper. Res. Soc. 1981, 32, 783-792. [CrossRef]

28. Fang, X.; Li, F.; Hu, Q.; Wei, Y. Strategic CBDR Bidding Considering FTR and Wind Power. IET Gener. Transm. Distrib. 2016, 10, 2464-2474. [CrossRef] 
29. Wang, B.; Fang, X.; Zhao, X.; Chen, H. Bi-level optimization for available transfer capability evaluation in deregulated electricity market. Energies 2015, 8, 13344-13360. [CrossRef]

30. Fang, X.; Li, F.; Wei, Y.; Cui, H. Strategic scheduling of energy storage for load serving entities in locational marginal pricing market. IET Gener. Transm. Distrib. 2016, 10, 1258-1267. [CrossRef]

31. Kazempour, S.J.; Conejo, A.J.; Ruiz, C. Strategic generation investment using a complementarity approach. IEEE Trans. Power Syst. 2011, 26, 940-948. [CrossRef]

32. Cui, H.; Li, F.; Fang, X.; Chen, H.; Wang, H. Bi-Level Arbitrage Potential Evaluation for Grid-Scale Energy Storage Considering Wind Power and LMP Smoothing Effect. IEEE Trans. Sustain. Energy 2018, 9, 707-718. [CrossRef]

33. Fang, X.; Li, F.; Gao, N. Probabilistic Available Transfer Capability Evaluation for Power Systems with High-Penetration Wind Power. In Proceedings of the 13th International Conference on Probabilistic Methods Applied to Power Systems (PMAPS), Durham, UK, 7-10 July 2014; pp. 1-6.

34. Kazempour, S.J.; Conejo, A.J. Strategic generation investment under uncertainty via Benders decomposition. IEEE Trans. Power Syst. 2012, 27, 424-432. [CrossRef]

35. GAMS. Available online: http:/ / www.gams.com/ (accessed on 10 May 2018).

36. California ISO I OASIS. Available online: http:/ / oasis.caiso.com/mrioasis/logon.do (accessed on 10 May 2018).

(C) 2018 by the authors. Licensee MDPI, Basel, Switzerland. This article is an open access article distributed under the terms and conditions of the Creative Commons Attribution (CC BY) license (http://creativecommons.org/licenses/by/4.0/). 